\title{
Experimental on the liquid cooling system with thermoelectric for personal computer
}

\author{
Osot Khonsue
}

Received: 9 March 2011 / Accepted: 23 May 2012/Published online: 8 June 2012

(C) The Author(s) 2012. This article is published with open access at Springerlink.com

\begin{abstract}
In the present experimental investigation, the liquid cooling in the micro channel fin heat sink with and without thermoelectric for central processor unit (CPU) of personal computer. The micro channel heat sinks with two different channel height are fabricated from the aluminum with the length, the width and the base thickness of 28,40 , $2 \mathrm{~mm}$ respectively. The de-ionized water is used as coolant. Effects of channel height, coolant flow rate, and run condition of PC on the CPU temperature are considered. The liquid cooling in micro-rectangular fin heat sink with thermoelectric is compared with the other cooling techniques. The thermoelectric has a significant effect on the CPU cooling of PC. The experiments are performed at no load and full load conditions within 60 min after steady state, which the mass flow rate are $0.023,0.017$ and $0.01 \mathrm{~kg} / \mathrm{s}$. The results heat transfer rate increase with increasing coolant flow rate and higher channel. When comparing with the other cooling system, cooling system with thermoelectric gives the highest efficiency. However, thermoelectric has the high or low heat transfer rate from heat rejected and cooling capacity conditions.
\end{abstract}

\section{Introduction}

Increasing demand for higher performance of the electronic devices and the level reliability of the heat rejection largely requires for these devices. The development of the miniaturized technology, mini and micro-component has rapidly

\footnotetext{
O. Khonsue ( $\square)$

Department of Mechanical Engineering, Rajamangala University of Technology Isan Sakonnakhon, 199 Phungkonvaritchaphum Rd., Phungkon, Sakonnakhon 47160, Thailand e-mail: osot.kh@rmuti.ac.th
}

increased especially in the electronic engineering and other fields. Gao and Rowe [1] developed a theoretical model for calculating the cooling performance of an integrated thermoelectric micro cooler. Zhao and $\mathrm{Lu}$ [2] presented an analytical and numerical study effect of porosity on the thermal performance a micro channel heat sink. Xuan [3] investigated the effect of the thermal and contact resistances of ceramic plate in thermoelectric micro coolers. Chein and Chuang [4, 5] studied the micro channel heat sink performance with and without thermo-electric using nanofluids as coolants. Bhowmil [6] studied on the steadystate convective heat transfer of water from an in-line four electronic chips in a vertical rectangular channel.

Zhang et al. [7] study of a single-phase heat transfer of micro channel heat sink for electronic packages. Sauciuc [8] presented an electronics cooling advancement challenges and innovation needs. Kminaga Matsumura and Kurakane [9] studied on advanced water cooled heat sink using thermosyphon for electronic device. Naphon and Khonsue [10] studied on the convective heat transfer and pressure drop in the micro channel heat sink. Naphon and Wiriyasart [11] experimentally stuied the liquid cooling in the mini rectangular fin heat sink with and without thermoelectric for CPU.

To the best of author' knowledge, the papers presented the experimental investigation on the heat transfer in the microchannel have been reported. The objective of this paper is to study on the heat transfer characteristics of the micro fin heat sink with and without thermoelectric of CPU of PC. Effects of relevant parameter on the cooling CPU are considered.

\section{Experimental apparatus}

A schematic diagram of the experimental apparatus is shown in Fig. 1. The test loop consists of a set of PC, 
Fig. 1 Schematic diagram of experimental apparatus

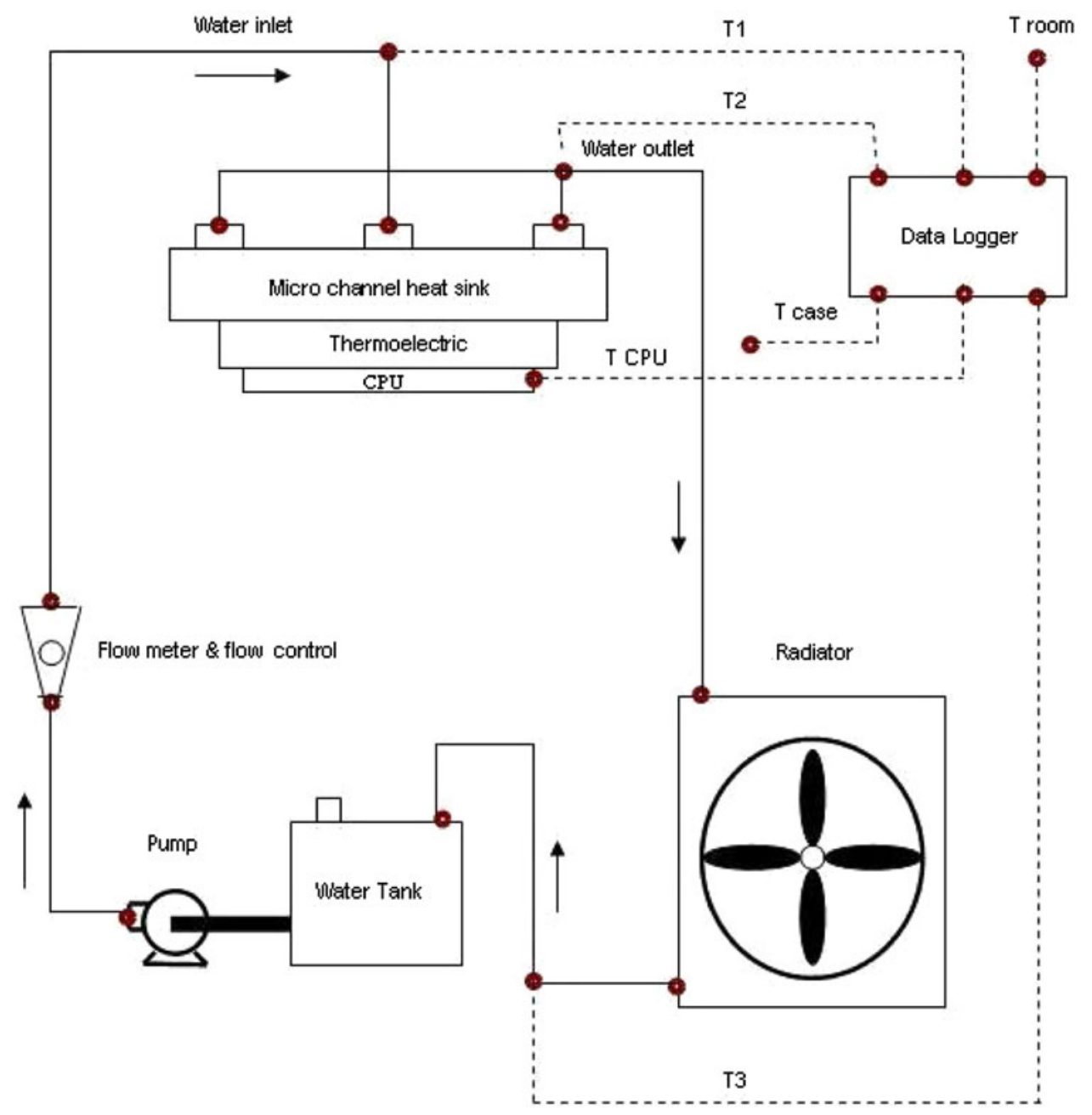

Table 1 Dimensions of the micro fin heat sinks

\begin{tabular}{lllll}
\hline Channel & $\begin{array}{l}\text { Fin } \\
\text { height } \\
(\mathrm{mm})\end{array}$ & $\begin{array}{l}\text { Fin } \\
\text { thickness } \\
(\mathrm{mm})\end{array}$ & $\begin{array}{l}\text { Channel } \\
\text { width } \\
(\mathrm{mm})\end{array}$ & $\begin{array}{l}\text { Size of heat } \\
\text { sink }(\mathrm{mm})\end{array}$ \\
\hline Aluminum & 1.5 & 0.20 & 0.30 & $40 \times 28 \times 2$ \\
Aluminum & 1.0 & 0.20 & 0.30 & $40 \times 28 \times 2$ \\
\hline
\end{tabular}

cooling de-ionized water loop and data acquisition system. The test section and the connections of the piping system are designed such that parts can be changed or repaired easily. The close-loop of de-ionized water consists of storage tank, water pump, flow meter, and radiator. The cooling de-ionized water is chilled by the atmospheric air. After the temperatures of the water are cooled to achieve the desired level, the cooling water is pumped out of the storage tank, and is passed through a flow meter, CPU and returned to the storage tank. The flow rates of the cooling water are controlled by adjusting the valve and measured by the flow meter. The test sections fabricated from the blocks of aluminum with the details are listed in Table 1.

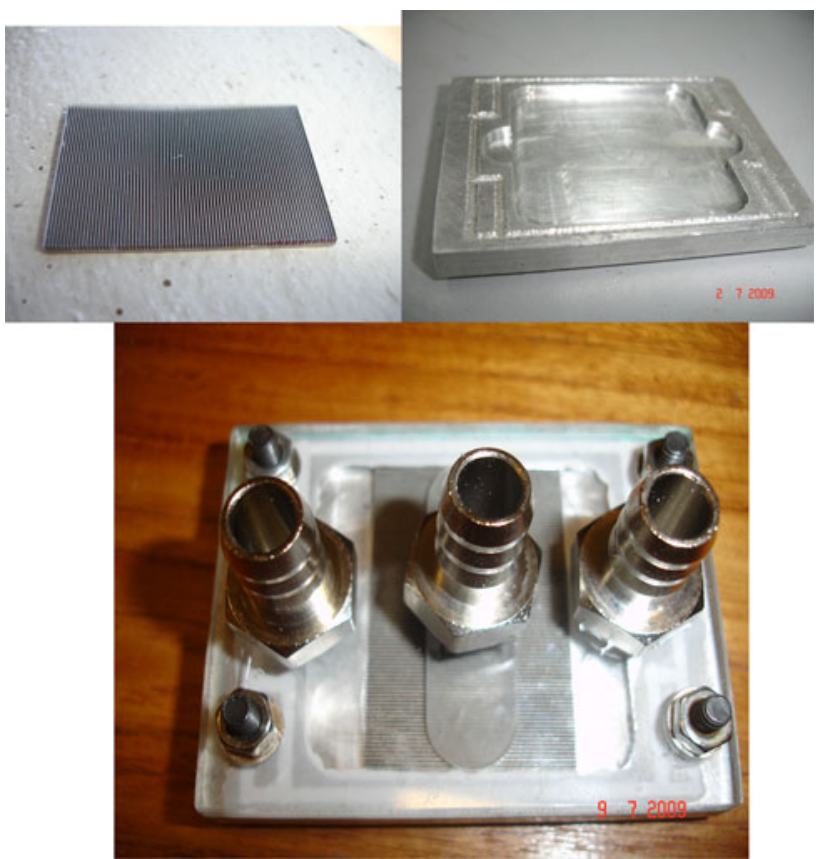

Fig. 2 Photograph of the micro fin heat sink components 

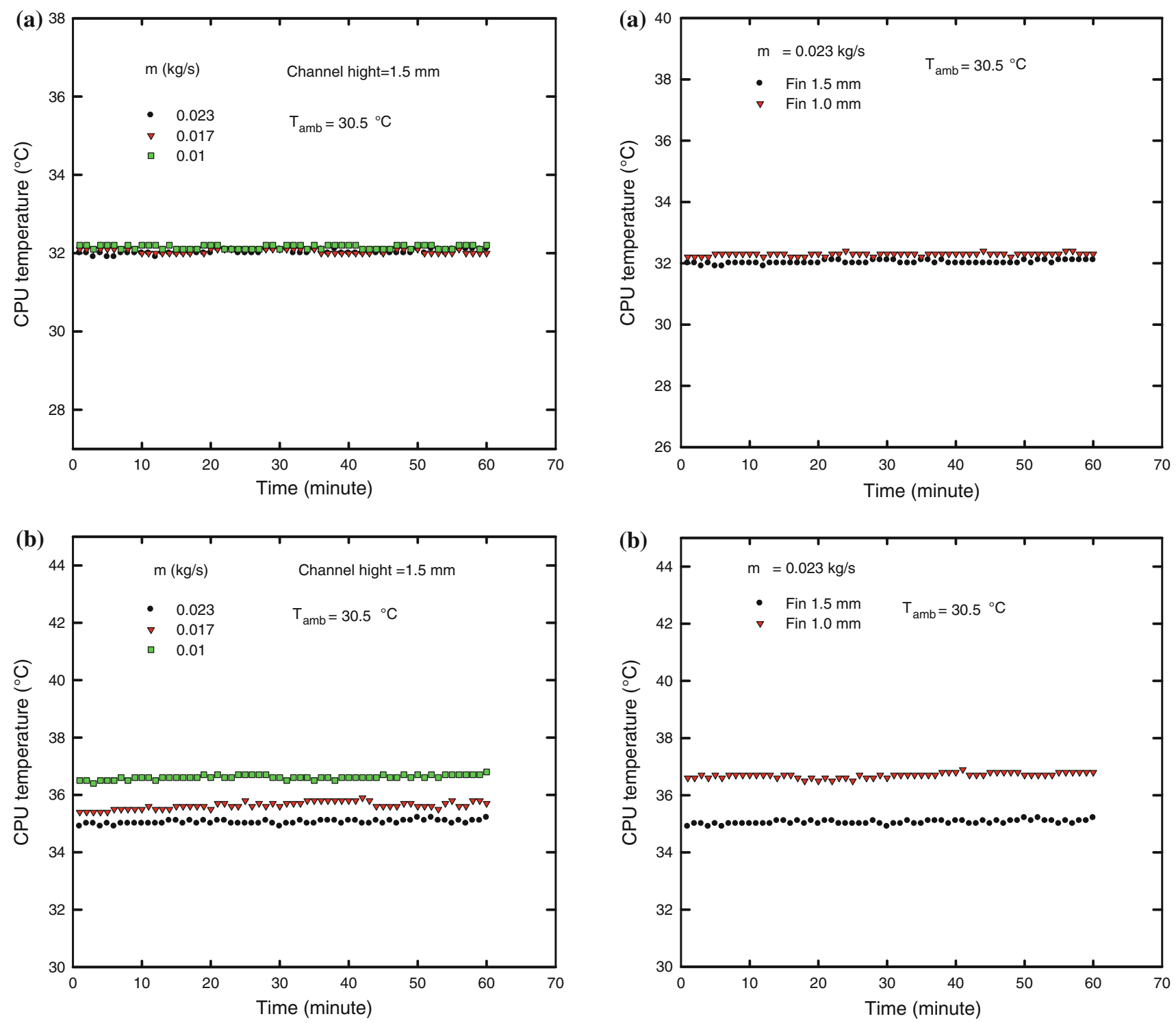

Fig. 3 Effects of coolant flow rate on CPU temperature for (a) no load conditions and (b) full load conditions

Fig. 4 Effects of channel height on CPU temperature for (a) no load conditions and (b) full load conditions

Adjusted to achieve the desired level by setting run condition of PC.

\begin{tabular}{lll}
\hline Instruments & Accuracy (\%) & Uncertainty \\
\hline Power supplied & 0.2 & \pm 0.5 \\
Flow meter & 0.2 & \pm 0.5 \\
Thermocouple type T, data logger & 0.2 & \pm 0.1 \\
\hline
\end{tabular}

The measured temperatures of cooling water at various positions are shown in Fig. 1.

The micro fin heat sink unit was shown in Fig. 2. Experiments were conducted with various cooling water flow rates, channel height of heat sink, and run condition of PC. The supplied load into the CPU was adjusted to achieve the desired level by setting run condition of PC.

\section{Results and discussion}

Each condition of the experiment was performed at the room temperature of $30-31{ }^{\circ} \mathrm{C}$ in the period time of $60 \mathrm{~min}$ for the steady state condition. The cooling water in the radiator was cooled by the atmospheric air at this temperature. Therefore, the inlet temperature of coolant water before entering the cooling section. In the present study, the cold side of thermoelectric is attached on the CPU of computer while the hot side of thermoelectric is attached with heat sink. The heat is removed from the cold side to 


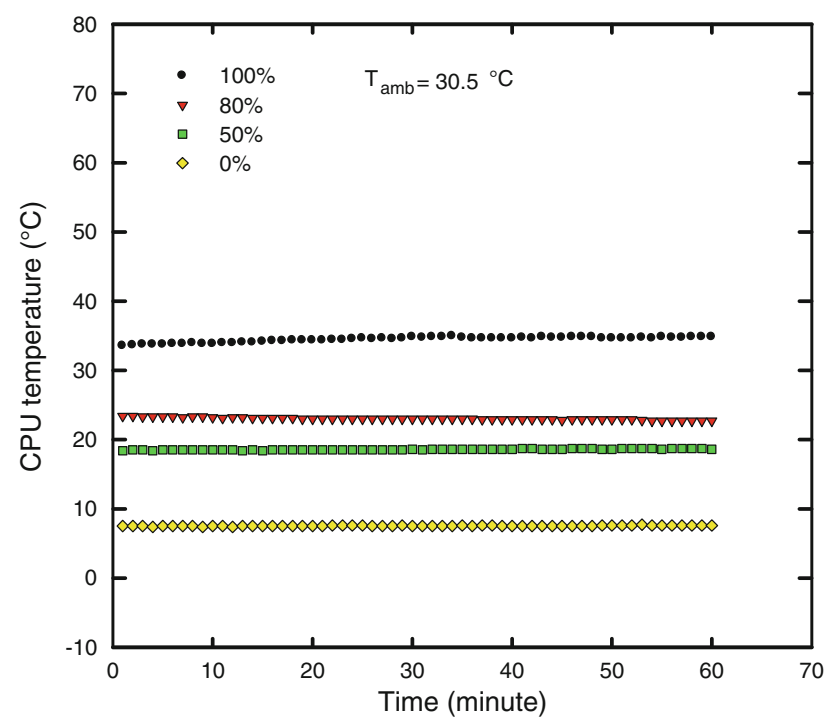

Fig. 5 Variations of CPU temperature with time for different load conditions

the hot side when the electric current passes through the module and then removed to the heat sink. Effects of cooling flow rate on the CPU temperatures for different load conditions of the aluminum heat sink with the channel height of $1.5 \mathrm{~mm}$ are shown in Fig. 3. For the three different coolant flow rates, a larger CPU temperature drop is found for a larger coolant flow rate. A larger coolant flow rate results in lower capacity resistance and consequently lower heat sink thermal resistance (Table 2).

Figure 4 shows the effect of channel height of heat sink on the CPU temperature of PC for no load condition and full load condition. Due to higher heat transfer surface area, the heat transfer rate from CPU to the heat sink increases. Therefore, the CPU temperatures obtained from the heat sink with higher channel height are lower than those with lower channel height, especially for full load condition. It can be seen from the figure that the CPU temperatures for the full load condition are higher than those from the no load condition for the whole range of the period time as shown in Fig. 5. This is because the full load condition generates the heat higher than the no load condition. The CPU temperatures obtained from the liquid cooling for micro fin heat sink with thermoelectric are compared those from the other cooling techniques as shown in Fig. 6a. The CPU temperature and the energy consumption obtained from the water cooling with thermoelectric technique are compared with those from the full load condition as shown in Fig. 6b.

The CPU temperature obtained from the water cooling without thermoelectric technique, water cooling with thermoelectric technique, air cooling with heat pipe
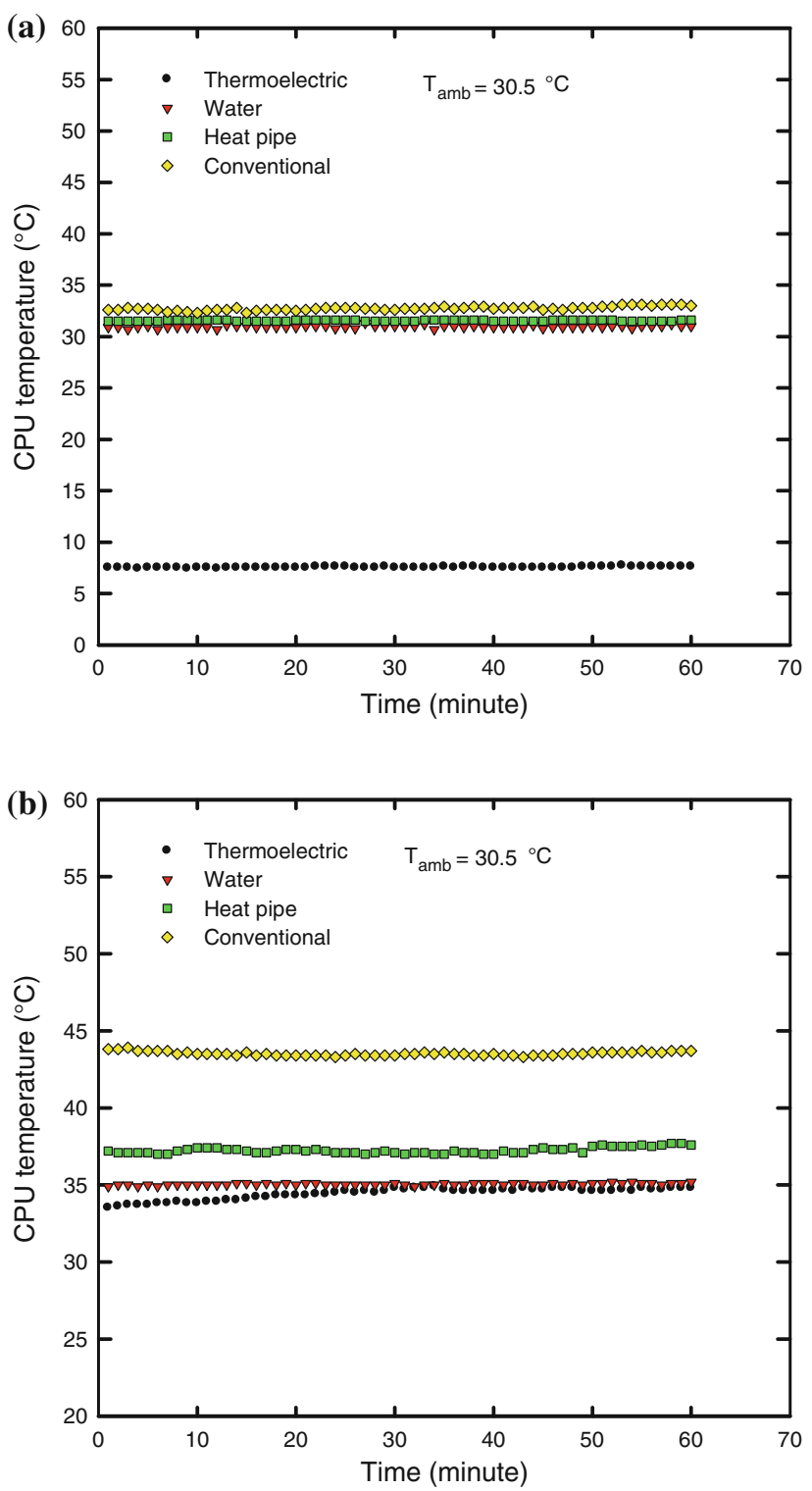

Fig. 6 Effects of cooling technique on $\mathrm{CPU}$ temperature for (a) no load conditions and (b) full load conditions

Table 3 Comparison of the temperature between various cooling techniques with air cooling technique

\begin{tabular}{lll}
\hline Cooling techniques & \multicolumn{2}{l}{ CPU temperature } \\
\cline { 2 - 3 } & No load $(\%)$ & Full load $(\%)$ \\
\hline Water cooling with thermoelectric & -77.00 & -22.21 \\
Water cooling & -5.50 & -19.21 \\
Air cooling with heat pipe & -3.33 & -14.45 \\
\hline
\end{tabular}

technique, are compared with those from the conventional air cooling technique where the plus symbol is represented the higher value while the minus symbol is represented the 
lower value as compared with the value from the air cooling technique. It can be seen from Table 3 that thermoelectric has significant effect on the cooling of the CPU of PC.

\section{Conclusions}

Due to the air cooling limitation of the electronic devices with high level of heat generation, the liquid cooling in the micro fin channel heat sink with and without thermoelectric for CPU has been investigated with de-ionized water as working fluid. Effect of channel height of heat sink, coolant flow rate and run condition of PC on the CPU temperature are considered. The results obtained from this technique are compared with those from other cooling techniques. The results of this study are expected to lead to guidelines that will allow the design of the cooling system with improved heat transfer performance of the electronic devices.

Acknowledgments The authors would like to express their appreciation to the Rajamangala University of Technology Isan Sakonnakhon (RMUTI) for providing financial support for this study.

Open Access This article is distributed under the terms of the Creative Commons Attribution License which permits any use, distribution, and reproduction in any medium, provided the original author(s) and the source are credited.

\section{References}

1. Gao M, Rowe DM (1999) Cooling performance of integrated thermoelectric microcooler. Solid-State Electron 43:923-929

2. Zhao CY, Lu TJ (2002) Analysis of microchannel heat sink forelectronics cooling. Int J Heat Mass Transf 45:4857-4869

3. Xuan XC (2003) Investigation of thermal contact effect on thermoelectric coolers. Energ Conserv Manage 44:399-410

4. Chein R, Huang G (2004) Thermoelectric cooler application in electric in electric cooling. Appl Therm Eng 24:2207-2217

5. Chein R, Chen Y (2005) Performance of thermoelectric cooler integrated with microchannel heat sinks. Int J Refrig 28:828-839

6. Bhowmil H (2005) Convection heat transfer from discrete heat sourced in a liquid cooled rectangular channel. Appl Therm Eng 25:2532-2542

7. Zhang HY, Pingala D, Wong TN, Toh KC, Joshi YK (2005) Single- phase liquid cooled micro channel heat sink for electronic packages. Appl Therm Eng 25:1472-1487

8. Sauciuc I (2008) Electronics cooling advancement, challenges and innovation needs, In: International Proceeding of the 9th international heat pipe symposium, pp 1-12

9. Kaminaga F, Matsumura K, Kurakane T (2008) Study on advanced water cooled heat sink using thermosyphon for electronic device, international proceeding of the 9th international heat pipe symposium, pp 222-226

10. Naphon P, Khonsue O (2009) study on the convective heat transfer and pressure drop in the micro channel heat sink. Int $\mathrm{J}$ Heat Mass Transf 36:39-44

11. Naphon P, Wiriyasart S (2009) liquid cooling in the mini rectangular fin heat sink with and without thermoelectric for CPU. Int J Heat Mass Transf 36:166-171 